Artigos

\author{
Gabriela Manitta Venditti \\ Universidad Andrés Bello \\ Diego Ochoa Herrera \\ Universidad Andrés Bello \\ Juan Emilio Ortiz Navarro \\ Universidad Andrés Bello
}

\title{
Maternidad y sublimación: una lectura psicoanalítica de la maternidad tardía
}

\begin{abstract}
Resumen: En este trabajo nos proponemos interrogar el fenómeno de la maternidad tardía desde la perspectiva del psicoanálisis. Centramos nuestro estudio en dos nociones: la de tiempo, asociada al funcionamiento del cuerpo femenino; y la de creación, en relación a la procreación humana. Ambas, tiempo y creación, están contenidas, para la teoría psicoanalítica, en el concepto de sublimación, representando una vía de abordaje singular de la feminidad y, en particular, de la maternidad como uno de sus destinos.
\end{abstract}

Palabras Clave: maternidad tardía; sublimación; feminidad; pocreación; Psicoanálisis.

Copyright (c) 2013 by Revista Estudos Feministas.

\section{Introducción}

Los especialistas en el tratamiento médico de la infertilidad explican que un creciente número de mujeres latinoamericanas han comenzado a postergar la maternidad por razones laborales y/o profesionales, de modo que inician la búsqueda de su primer embarazo después de los 35 años, cuando la capacidad biológica de sus óvulos para ser fecundados es cualitativamente inferior a la de una mujer de 25 años, capacidad que disminuye drásticamente promediando los 40 años. Esta es una de las razones por la que algunos centros de medicina reproductiva ya realizan tratamientos con óvulos de donantes.

Nada impide otorgar a los datos médicos la validez que les corresponde. No es eso lo que está en duda aquí, 
'Los casos donde el "descuido" efectivamente acontece y es seguido de un aborto voluntario no serán objeto de este estudio, como tampoco el llamativo contraste entre el control anticonceptivo sin fisuras que son capaces de ejercer algunas mujeres, y la alta tasa de embarazo en adolescentes chilenas asociado actualmente por las autoridades sanitarias a dificultades para hacer un uso efectivo de dicho control. Debido a la extensión de este trabajo, no es posible incluir estas dos problemáticas que sin embargo consideramos de gran relevancia para futuras investigaciones.

${ }^{2}$ Rosario SAMPEDRO, Ma. Victoria GOMEZ, Mercedes MONTERO, 2002, p. 13.

${ }^{3}$ Jacques LACAN, 2002, p. 256. sino más bien el aparente acuerdo generalizado acerca de las razones por las cuales una mujer posterga la maternidad hasta el límite de lo biológicamente posible para su cuerpo. Se dice que esto se debe a que las mujeres profesionales o laboralmente activas, dedican todo su esfuerzo y tiempo al trabajo, de manera tal que sólo cuando han afianzado su posición laboral o profesional comienzan a desear convertirse en madres.

Sin embargo, hay un detalle que se repite en el discurso de algunas mujeres a quienes se ha tenido oportunidad de escuchar en el contexto del apoyo psicológico que ofrecen algunos centros de reproducción asistida. Nunca, durante toda su vida sexualmente activa, han sufrido algún 'descuido': olvidar tomar la píldora, no usar preservativo, mantener relaciones sexuales sin métodos de barrera durante sus días fértiles, ${ }^{1}$ etc. Un detalle no es una explicación, pero representa a veces un punto de interrogación: o existió un deseo de hijo que por alguna razón debió ser férreamente reprimido, o su 'deseo' estuvo encausado por otros intereses diferentes a la maternidad biológica.

Las variables sociales, históricas y antropológicas que atraviesan el fenómeno que se ha denominado maternidad tardía como causa de infertilidad, deberían ser consultadas a fin de situar el contexto de la problemática a estudiar, pero este trabajo no se inscribe como contribución a dichas disciplinas de estudio. Por lo que no pretendemos explicar por qué un creciente número de mujeres se encuentran en la situación que antes describimos.

Nuestro campo de trabajo se sitúa en la brecha, que permanece escasamente estudiada, entre el dato biomédico (edad reproductiva de la mujer) y el dato sociohistórico-cultural (acceso creciente de las mujeres al campo laboral y al ejercicio profesional). Buscamos interrogar la maternidad tardía más allá de la aptitud de los óvulos pasada cierta edad, y más acá de las preocupaciones demográficas que insisten en recordar la importancia de la "productividad biológica" femenina para asegurar el reemplazo esperado de las generaciones. ${ }^{2}$ Si bien hay un límite biológico para la fecundidad femenina, nos preguntamos con qué criterio se podría establecer una edad adecuada, ni temprana ni tardía, para el ejercicio subjetivado de la maternidad.

\section{El aplazamiento de la maternidad}

Proponemos considerar la infertilidad asociada al aplazamiento de la maternidad como un "accidente biográfico" ${ }^{3}$ en la historia particular de aquella mujer que se sorprende de no estar embarazada después de haber 
${ }^{4}$ Marie-Magdeleine CHATEL, 1996 p. 75.

${ }^{5}$ Michel TORT, 1994, p. 158. suspendido los métodos anticonceptivos durante largo tiempo. Pero no le sorprende en absoluto que el embarazo no haya sucedido antes, por error, por olvido, por azar, en el encuentro con un hombre. Como señala Marie-Magdeleine Chatel:

Querer un hijo, tal y como se proclama esto hoy en día, es tan extraño al y está tan alejado del deseo que hay que carecer de uno para poder quererlo de esta manera, es decir sin hacerlo. Puesto que antes, señalémoslo, lo hacían sin saber si lo querían o no. iQuerer un hijo sin hacerlo entraña algo de forzado! No se puede querer sino lo que no se tiene o lo que se ha perdido. ${ }^{4}$

Lo que no se tiene o se ha perdido es el deseo de hijo, no el hijo ni la capacidad biológica para concebirlo. Esa es la hipótesis de Chatel y es lo que verificamos en la clínica de la infertilidad en una gran cantidad de casos. Incluso cuando la medicina informe que dicha capacidad biológica para concebir está comprometida.

Porque casi siempre los médicos verifican algún obstáculo a nivel de la capacidad ovárica, tubular o de implantación, entre otras. A veces no se encuentra ninguno y se diagnostica entonces Infertilidad de Causa Médica Desconocida (ICMD). Y sin embargo, provocan asombro los embarazos contra todo pronóstico, en casos de endometriosis severas, mala calidad de los óvulos, etc. Como también asombra constatar que muchas mujeres que sí han podido concebir hijos, tienen las mismas dificultades biológicas que las que no lo consiguen. Al respecto, Michel Tort apunta:

En muchos de los casos informados por los ginecólogos, el embarazo sobreviene 'por sorpresa', 'por milagro', sin que nada en lo real del cuerpo permita explicarlo. A decir verdad, lo sorprendente es asombrarse de esa 'sorpresa'. El asombro muestra hasta qué punto las condiciones inconscientes del deseo de hijo son espontáneamente negadas: en realidad pensamos que el universo del querer afirmado y su competencia deberían producir un hijo. Los embarazos milagrosos para el ginecólogo no lo son más que los comunes, que, maravillas del deseo fugitivo, siempre lo son. ${ }^{5}$

Resulta tal vez necesario en este punto reiterar que los embarazos asombrosos o médicamente inexplicables no ponen en duda la capacidad médica de diagnóstico o tratamiento de la infertilidad femenina, sino que hacen evidente la diferencia que destacó Jacques Lacan entre la dimensión de la 'demanda' - el querer declarado y consciente - y la del 'deseo's siempre inconsciente y en tanto tal fugitivo.

En otras palabras, decidir tener un hijo no equivale necesariamente a desear convertirse en madre o a desear 
${ }^{7}$ Paul-Laurent ASSOUN, 1994, p. 29.

${ }^{8} \mathrm{Cf}$. Jacques-Alain MILLER, 2002.

${ }^{9}$ Cf. LACAN, 2002a.

${ }^{10}$ LACAN, 2002, p. 256. un hijo. En muchos casos la decisión de tener un hijo responde más bien a un esfuerzo por satisfacer ideales culturales o familiares en la dirección de una ganancia narcisística. Como señala Paul-Laurent Assoun:

De pronto se entiende que la 'esterilidad' de la mujer -tratada por los discursos y prácticas de la modernidad social como un perjuicio que debe ser 'tratado'[...]también pueda ser la prueba misma de una cuestión que confronta a la mujer con un deseo de niño que sea realmente suyo. ${ }^{7}$

La pregunta acerca de por qué cuando se decide finalmente tener un hijo no se consigue hacerlo, sólo se despliega allí donde el cuerpo se manifiesta como sede de acontecimientos inexplicables, ${ }^{8}$ tanto por lo que se puede hacer con él - torcer, forzar sus coordenadas instintivas, por ejemplo con una píldora anticonceptiva - como por lo que no se consigue que en él se produzca, a pesar de quererlo, un embarazo en el momento en que se decide. El cuerpo, afirmaba Lacan, está hecho para 'gozar',' esto es, para extraer de él una ganancia, 'plus de goce', una diferencia entre lo que la pauta instintiva ordena para el funcionamiento del organismo y las marcas que el significante es capaz de producir en ese organismo en tanto cuerpo de un sujeto que habita un universo simbólico. No obstante:

Existe de todos modos una cosa que escapa a la trama simbólica, la procreación en su raíz esencial: que un ser nazca de otro. La procreación está cubierta, en el orden de lo simbólico, por el orden instaurado de esa sucesión entre los seres. Pero nada explica en lo simbólico el hecho de su individuación, el hecho de que un ser sale de un ser. Todo el simbolismo está allí para afirmar que la criatura no engendra a la criatura, que la criatura es impensable sin una fundamental creación. Nada explica en lo simbólico la creación. ${ }^{10}$

Para el animal, todo sucede conforme a lo que le indica la pauta instintiva en cuanto a ciclos de celo y apareo, fijos y repetitivos en el tiempo, que finalmente reproducen la especie. En cambio para el ser humano, el acceso a la maternidad/ paternidad se produce como resultado de un acto fundamental de creación procreación y no reproducción - cuyo producto es un hijo, que será luego inscripto en un linaje, en un orden simbólico que lo situará en la sucesión entre otros seres semejantes.

¿En qué consiste entonces ese acto fundamental de creación que precede toda posibilidad de pensar una nueva creatura? Proponer con Lacan el término 'procreación' para lo que tiene de específicamente humano la

776 Estudos Feministas, Florianópolis, 21(3): 773-791, setembro-dezembro/2013 
"Sigmund Freud describió la sublimación como un destino pulsional en donde la meta y el objeto de la pulsión han sido desviados de modo tal que ésta alcanza su satisfacción resignando la meta sexual por otra no sexual de valoración social superior.

${ }^{12}$ LACAN, 1997, p. 257.

${ }^{13}$ Joan COPJEC, 2006, p. 68. reproducción de nuestra especie, es poner en evidencia la satisfacción de algo más que las leyes de la supervivencia en dicho acto procreativo.

En su seminario sobre la Ética del Psicoanálisis, Lacan retoma los estudios freudianos ${ }^{11}$ acerca de la sublimación para destacar en ella - en tanto que destino pulsional - su carácter "creacionista". ${ }^{12}$ En otras palabras, se trata allí de la pulsión que en su trayecto alrededor de un vacío es capaz de crear ex nihilo su objeto. Si la procreación humana es un acto de creación que se efectúa a propósito de un agujero en lo simbólico, y la sublimación consiste en "la creación pulsional ex nihilo de un objeto"13 en ese mismo vacío ¿Es posible establecer una relación entre la procreación humana y la sublimación tal como las define Lacan? De ser así, ¿en qué consistiría la procreación en tanto sublimación?

La procreación humana, desde la perspectiva del psicoanálisis, es fundamentalmente un hecho cultural en tanto no obedece a las leyes del instinto, sino a las del deseo. Nada explica de otra forma los recursos de los que puede valerse una mujer para postergar, o incluso abolir entre sus intereses, la maternidad. En esta misma dirección, Yvonne Knibiehler ${ }^{14}$ recorre la historia de la maternidad en Occidente y encuentra que la naturalización de la maternidad y su glorificación fue un fenómeno que se impuso en Europa sobre todo entre los siglos XIX y XX. La invención de la buena madre fue el resultado de una compleja trama de hechos sociales, políticos y económicos en medio de los cuales la madre devino un sujeto histórico, capaz de influir en el futuro de sus hijos y de contribuir al crecimiento de las naciones mediante su natural aptitud y predisposición para los cuidados de los hijos.

Con sus formulaciones, Sigmund Freud también cuestiona la pretendida naturalidad de la maternidad como destino para el sujeto femenino, en tanto hace del producto de la procreación humana un destino de pulsión - objeto que sustituye al objeto primordial -y a la operación mediante la cual éste se engendra un acto, metaforizado por la cultura y ligado a la valoración social o moral de la época.

Por otra parte, si la sublimación como mecanismo psíquico facilita a la pulsión una vía para la satisfacción sin represión - es decir, al margen de las exigencias de la realidad y las del yo -, ¿podría sostenerse que el objeto de la sublimación tenga que ser un objeto socialmente valorado? La referencia a la valoración social ino introduce una exigencia de otro tipo, en el orden del ldeal?

Joan Copjec, siguiendo el recorrido de Lacan en su Seminario sobre la Ética, destaca que la sublimación no equivale a la sustitución de un objeto que produce satisfacción sexual inmediata por otro valorado por la 
${ }^{15}$ COPJEC, 2006, p. 95.

\begin{abstract}
${ }^{16}$ Sigmund FREUD, 2004, p. 174. 17 Considerando la extensión y objeto de este trabajo, no nos es posible detenernos en la definición de éste término cuya elaboración en la obra lacaniana reviste gran complejidad. No obstante y a fin de facilitar la comprensión de nuestro asunto, definiremos aqui el término Real siguiendo el ordenamiento que propone J.-A. Miller, según lo que él identifica como paradigmas del goce en la obra de Lacan (Cf. MILLER, 2000, p. 150-54). A la altura del Seminario de "La Ética", Lacan trabaja con la noción de Real como aquello que se encuentra más allá del equilibrio homeostático del Principio del Placer freudiano. Se trata allí de los excesos del goce, es decir, de aquello con lo que se encuentra el sujeto cuando transgrede los límites del Principio del Placer. Por encontrarse po fuera de todo significante y significado, no es posible acceder a lo Real a través del orden simbólico. De manera semejante, lo Real es aquello que se encuentra tras la barrera de lo bello que representa el orden imaginario. En otras palabr as, cuando se trata de lo Real, de un lado encontramos aquello que es del orden del artificio, lo Imaginario; y lo que es del orden del significante, lo Simbólico. Más allá de aquello y franqueando la barrera del placer, transgresión mediante, hayamos el horror y el sufrimiento, lo Real. (Cf. MILLER, 2000).

${ }^{18}$ Massimo RECALCATI, 2006, $\mathrm{p}$. 43.

19 Jean LAPLANCHE, 2002, p. 30
\end{abstract}

cultura, en tanto que el trayecto de la pulsión hacia el objeto y de vuelta hacia el sujeto no es un trayecto de reflexión selección de objetos socialmente valorados -, ni de identificación - al ideal cultural vigente -, sino de obtención de satisfacción. Por lo tanto, el rasgo peculiar del objeto de la pulsión en la sublimación no depende en principio de su valor cultural o social en relación con otros objetos o con el Otro social. Su valor excedente - valor de goce - "depende exclusivamente de que la pulsión lo haya elegido como objeto de satisfacción". ${ }^{15}$

Discernir la incidencia de la valoración social en la elección del objeto en la sublimación es un asunto central al tema que nos compete. Ya Freud había postulado la maternidad como efecto sublimatorio del lado femenino. Si bien consideraba que a las mujeres les era concedido en menor grado el don de sublimar la pulsión, afirmaba que a ellas "[...] les basta, sí, el lactante, pero no el hijo crecido como sustituto del objeto sexual". ${ }^{16}$ Ahora bien, la maternidad en tiempos de Freud no revestía el mismo valor social que en la actualidad, donde las mujeres pueden escoger ser madres o no serlo, en relación a una paleta de intereses que van desde el arte a la profesión, pasando por la política y la vida laboral. En otras palabras, podríamos concluir rápidamente diciendo que si en los últimos años las mujeres postergan cada vez más la maternidad, será porque se han hecho accesibles para ellas otros destinos, también valorados socialmente.

No obstante, resulta necesario interrogar aquello de la valoración social tal y como parece comprenderse, puesto que de ser así, la sublimación no sería más que otra forma de normalización del goce femenino, para nuestro caso.

\section{Lacan: la sublimación como elogio del vacío}

Lacan abordará de forma extensa, aunque no exclusiva, el estudio del problema de la sublimación en su seminario sobre la Ética del Psicoanálisis. Su operación allí consistirá "en preservar la sublimación en relación a lo Real ${ }^{17}$ y no al ldeal". ${ }^{18}$

Los desvíos post-freudianos en torno a la sublimación hicieron de ella, al decir de Jean Laplanche, "una de las cruces del psicoanálisis"19. Por una parte se redujo su alcance a una finalidad normalizante, al proponer la sublimación como el mecanismo que conseguiría cierta domesticación de la pulsión al servicio de la cultura, incluso de la salud mental. Por otro lado, se volvió cada vez más engorroso dar cuenta de la satisfacción sin represión inherente a la sublimación, tal como la definió Freud, al 
${ }^{20}$ LACAN, 1997, p. 138.

21 Cf. RECALCATI, 2006.
${ }^{23}$ LACAN, 1997, p. 166. En la elaboración de la noción de Cosa - Das Ding, Lacan toma prestado de Heidegger el modelo del vaso según el cual, el vaso es un objeto creado que introduce una nueva presencia - un más - en el mundo. Pero al mismo tiempo, el vaso tiene paradójicamente la propiedad de introducir un vacío - un menos y con ello la posibilidad de un complemento capaz de llenarlo (Cf. MILLER, 2000). La madre como objeto primordial es aquí el paradigma de Das Ding. Se trata del primer exterior que funda el andar de sujeto, el Otro absoluto, prehistórico, inolvidable e inalcanzable, objeto perdido que se trata siempre de volver a encontrar. Esa orientación de la acción al reencuentro de Das Ding es lo que Lacan, a la altura del Seminario "La Ética", define como Neurosis (p. 68-69). Por el contrario, la elevación de un objeto ordinario a la dignidad de la Cosa, que es el movimiento de la sublimación, depende de que aquel Objeto fundamenta permanezca ausente, perdido.

${ }^{24}$ RECALCATI, 2006, p. 79. punto de no poder ya distinguir los usos de este mecanismo en las diferentes estructuras clínicas.

Lacan no desatiende todos estos desvíos, pero retoma el asunto por lo que hace a su novedad, esto es que:

La sublimación aporta a la pulsión una satisfacción diferente de su meta - definida como su meta natural - y eso es lo que revela la naturaleza propia de la pulsión en la medida en que ésta no es puramente instinto, sino que se relaciona con la Cosa, en tanto que ella es diferente del objeto. ${ }^{20}$

Es mediante el estudio de la sublimación que Lacan consigue precisar de qué manera el goce pulsional, a diferencia del instinto, no apunta al hallazgo de un objeto idóneo para la satisfacción inmediata de tal o cual necesidad $^{21}$. La pulsión, por el contrario, encuentra su satisfacción en el trayecto alrededor de un objeto y luego de vuelta hacia el sujeto.

La novedad lacaniana en el tratamiento de la sublimación consiste en definirla como aquella operación mediante la cual un objeto ordinario es "elevado a la dignidad de la Cosa". ${ }^{22}$ Afirmar que un objeto ordinario puede ser idóneo para esta operación es otra forma de subrayar o hacer evidente que la satisfacción pulsional que se obtiene por la vía de la sublimación no consiste ni en llenar un vacío, ni en recuperar algo perdido, como tampoco en ocultar lo Real de una ausencia; es justamente a propósito de esa ausencia que la pulsión se hace de un objeto.

Lo importante a tener en cuenta aquí es que la Cosa es ella misma ausencia, lo que implica la imposibilidad lógica de concebirla como preexistente a cualquier tratamiento significante que se le pueda dar. En otras palabras, la Cosa o Das Ding es para Lacan "efecto de la incidencia del significante sobre lo real psíquico". ${ }^{23}$

Así, Lacan identificará tres modalidades de tratamiento de lo Real, dada la imposibilidad lógica antes mencionada - que la Cosa preexista a la elaboración que inscribe su ausencia -, que fundan por su misma operación una estructura simbólica, en cuyo seno hay vacío: la religión, la ciencia y el arte.

La religión consistirá en evitar el vacío, oponiendo mediante la creencia una saturación de sentido allí donde emerge el sin sentido. La Ciencia hará lo propio, rechazando la presencia de la Cosa mediante la soldadura de sentido. Por fin, el arte consistirá en la organización de ese vacío mediante "un trabajo simbólico que se despliega alrededor de un agujero real", ${ }^{24}$ aprovechando simbólicamente el empuje pulsional. 
${ }^{25}$ Lo irreductible es aquí otro nombre para la Madre como Das Ding - la Cosa - objeto perdido que se busca recuperar en cada sustitución.

${ }^{26}$ LACAN, 1997, p. 170.

${ }^{27}$ LACAN, 2002, p. 252.

${ }^{28} \mathrm{Cf}$. ANDRÉ, 2002.

${ }^{29}$ ANDRÉ, 2002, p. 272.

${ }^{30}$ MILLER, 1994, p. 85.

${ }^{31}$ LACAN, 2004, p. 89. "[...] La mujer solo puede escribirse tachando La. No hay La mujer artículo definido para designar el universal. No hay

La mujer puesto que [...] por esencia ella no toda es".

${ }^{32}$ MILLER, 1994, p. 85, el énfasis es nuestro.

${ }^{33}$ Cf. Serge ANDRÉ, 2002.

\section{La invención femenina}

Para Lacan la originalidad que caracteriza el trabajo freudiano reside en haber captado "la experiencia de lo irreductible ${ }^{25}$ en el fondo de las sustituciones histéricas". ${ }^{26}$ La riqueza creativa del síntoma histérico radica justamente en su capacidad para denunciar lo insoportable de una pérdida inicial.

Será en la prehistoria del Edipo femenino donde Freud sitúe, no sin dificultad, esa especie de desgarro que funda la feminidad y que consiste en dar por perdido el objeto primordial - la Madre como Das Ding - sin otra razón, a diferencia del varón, que la de asegurarse en adelante una vía posible para el deseo.

El sexo femenino tiene para Lacan un "carácter de ausencia, de vacío, de agujero" 27 en tanto la única referencia que distribuye las posiciones sexuales es el falo. Mientras que para el varón dicha referencia es suficiente para localizarse en el Otro como siendo hombre en relación a tener el falo; para la niña tal referencia se hace insuficiente en tanto no hay significante que la nombre como tal. Sólo le resta localizarse en el Otro como no teniendo el falo, pudiendo eventualmente serlo.

Como sostiene Serge André la feminidad se presenta como un devenir, no como un ser. Dado que el Otro es estructuralmente impotente para producir un signo de lo femenino como tal, la mujer debe ser casi fabricada por un largo trabajo psíquico. ${ }^{28}$ Así "una mujer no puede aprehender la feminidad sino indirectamente, por el sesgo de un artificio". ${ }^{29}$ Por lo que, dirá Jacques - Alain Miller, "llamamos mujeres a esos sujetos que tienen una relación esencial con la nada". 30

De la insuficiencia del Otro para designar lo femenino, se desprenden dos consecuencias: no es posible, por un lado, dar con un universal para la mujer - "La mujer no existe", ${ }^{31}$ afirma Lacan; y por otro lado, "la mujer no se puede descubrir, de tal manera que hay que inventarla". ${ }^{32}$

Lo expuesto hasta aquí nos permite introducir la relación esencial de las mujeres con el artificio y la creación, ya que -siempre que no quede entrampada en el esfuerzo de hacerle producir al Otro un signo que la localice - cada mujer deberá inventar para sí misma las razones que la conduzcan de la nostalgia por lo perdido a la producción de un significante que la nombre.

Cabe recalcar que los nombres que las mujeres se dan funcionan como semblantes de lo femenino, pero no agotan ni obturan el vacío que es su núcleo.

André ${ }^{33}$ sostiene que, en tanto lo femenino consiste en producir un significante nuevo que la nombre como tal, 
34 Jorge CHAMORRO, 2008, p. 109.

${ }^{35}$ ASSOUN, 1994, p. 221.

${ }^{36}$ FREUD, 2004, p. 174

37 Según Loffreda, han de considerarse como productos del trabajo sublimatorio tanto la producción de nuevos objetos o significantes, como la resignificación de los ya existentes (Cf. Enrique LOFFREDA, 1999). Gérard Wajcman, dentro del ámbito del arte, destaca también la preponderancia del efecto creador en la operación de subvertir la utilidad de un objeto rompiendo con su identidad real (Cf. WAJCMAN, 2001). A esto último se refiere también Lacan cuando define la sublimación como el acto de elevar un objeto ordinario a la dignidad de objeto de la pulsión (Cf. LACAN, 1997). resulta insuficiente la referencia freudiana a la ecuación simbólica pene $=$ hijo. Puesto que nada garantiza que en el pasaje que realiza la niña de la madre al padre, del padre al falo y del falo al niño se produzca por fuerza una sustitución metafórica - ejercicio que implica la aparición de una nueva significación. En otras palabras, para una mujer ser nombrada como Madre no garantiza, a pesar de lo dicho por Freud, nada de la feminidad, dado que la maternidad no escapa a la significación fálica.

Para Jorge Chamorro, la forma freudiana de pensar el camino de la feminidad consiste en metaforizar en el deseo de hijo el deseo de pene, "por eso en la mujer el deseo de falo es un deseo que encarna en la maternidad". ${ }^{34}$ Desde esta perspectiva la feminidad tendría en sí un elemento macho metaforizado vía la maternidad. O dicho de otra forma, la maternidad sería el resultado de hacer entrar el goce femenino en una lógica propiamente fálica.

\section{Sublimación y feminidad}

Podemos afirmar que si bien el mecanismo de la sublimación es uno y el mismo para los dos sexos, las razones por las cuales cada quien asume dicho trabajo son estructuralmente distintas.

En el caso de la mujer, la amenaza de castración no representa una razón para renunciar a la madre como objeto. Ella deberá darse la tarea de inventar razones para dejar atrás aquella pérdida fundante de su posición. Y al mismo tiempo, deberá "negociar con la pulsión de manera más ajustada el espacio de juego de la sublimación", ${ }^{35}$ puesto que es como procreadora que ella se encuentra comprometida en la función social.

La asunción de la posición femenina demanda a cada mujer un trabajo sublimatorio de modo tal que al final de ese recorrido ella pueda hacerse de un significante que la represente en el Otro. Y esto se debe a que - a diferencia del hombre - no existe en el Otro un significante de lo femenino como tal.

Paradójicamente, aunque a las mujeres "les es concedido en menor grado el don de sublimar la pulsión" 36 ellas requieren, para ser representadas como tales, del constante ejercicio sublimatorio cuyo producto es la invención significante, ${ }^{37}$ efecto del cual ellas logran, por una parte, hacerse de un lugar en el Otro social. Por otra parte, mediante el velamiento del vacío para nombrarlas, consiguen crear semblante de su posición sexuada.

Es justamente el abordaje de la sublimación desde la perspectiva de lo femenino lo que conduce a subrayar la importancia de no identificar la valoración social como 
${ }^{38}$ Lacan presagiaba la factibilidad de la partenogénesis para las mujeres con el auxilio de la Ciencia (LACAN, 2002, p. 455).

${ }^{39}$ LOFFREDA, 1999, p. 53. elemento característico del destino sublimatorio con la simple adopción, más o menos elegante, de los ideales vigentes en una época.

Por el contrario, el valor otorgado por la cultura a los productos del trabajo sublimatorio depende más bien de la aptitud de éstos para proporcionar cierta forma específica de satisfacción, en el límite de lo irrepresentable, sin padecer los efectos estragantes de una excesiva cercanía con lo Real.

La intuición freudiana que hacía de la maternidad un destino sublimatorio por excelencia para la mujer, se confirma sólo si ella consiente ocupar el lugar culturalmente asignado de guardiana de los intereses sexuales de la humanidad. En ese sentido, no toda mujer que es madre sublima, algunas sólo se limitan a la reproducción de los ideales culturales vigentes ${ }^{38}$ Es decir, reproducen la ficción de la maternidad como destino natural femenino - el ldeal de la mujer que 'se completa' siendo madre. Mencionábamos antes que el hijo como producto de la ecuación simbólica pene $=$ hijo, puede ocupar el lugar de un objeto sustituto (del objeto perdido primordial), objeto metonímico que promete colmar la falta por el lado del tener, pero que no la metaforiza necesariamente.

Otras mujeres, en cambio, hacen uso de ese destino incitado por el ldeal, para acceder, en el cruce con el deseo de Otro, a un significante que las nombra - Madre - pero que no tapona su falta en ser, sino que abre significaciones nuevas.

Enrique Loffreda entiende la valoración social como el "indispensable complemento participativo de la sublimación". ${ }^{39}$ Dicho complemento no equivale a la buena o mala acogida que determinado producto sublimatorio reciba de su época. Más bien representa la ineludible participación del Otro social en el circuito que completa el recorrido sublimatorio. En otras palabras, el reconocimiento social testimonia la apreciación de la que es objeto cualquier maniobra sublimatoria que produzca un acercamiento al vacío sin sufrir las consecuencias de su incandescencia.

Ahora bien, el reconocimiento de estas maniobras no se traduce necesariamente en la aceptación de determinada obra. Generalmente ocurre lo contrario, y es por la vía del rechazo que el Otro social acusa recibo de la verdad que el acto sublimatorio evidencia, esto es, la imposibilidad estructural para el ser hablante de acceder a un goce unificado o completo. O también, la insuficiencia significante para conjurar la amenaza de irrupción de lo Real.

Es por el carácter amenazante que todo acto sublimatorio representa - en tanto que velando devela un vacío - que la operación que conduce a cualquier forma de creación debe ser autónoma respecto de los ideales vigentes en la Cultura. Copjec subraya al respecto que no debe 
40 FREUD, 2004, p. 214.

${ }^{41}$ COPJEC, 2006, p. 76.

42 LACAN, 2002, p. 256.

${ }^{43}$ COPJEC, 2006, p. 77.

${ }^{44}$ Carlos KURI, 2007, p. 341-342 entenderse la sublimación como una operación que escinde el pensamiento del sexo - la "meta más alta de índole ya no sexual" 40 de la que hablaba Freud -, sino más bien del supuesto sujeto del conocimiento - el Otro. "En efecto, la satisfacción de la pulsión a través de la sublimación atestigua la autonomía del sujeto [...], su independencia del Otro". ${ }^{41}$

Es porque el sujeto ha renunciado al Ideal de una satisfacción sin resto - cuya posibilidad el Superyó atestigua y en razón de la cual eleva las exigencias de trabajo - que accede a una forma suplementaria de goce. La autonomía respecto del Otro equivale al reconocimiento de su inexistencia.

Se trata aquí de concluir en "un acto fundamental de creación" 42 que es a la vez testimonio de independencia del Otro - de aceptación de su inexistencia - y velo que recubre el vacío que se abre con ese hallazgo.

En este punto se hace preciso insistir en la diferencia fundamental entre sublimación e idealización. Retomando a Copjec, diremos que la idealización es en el fondo "idealización de la insatisfacción". ${ }^{43}$ Esto es, sostener en alto la ilusión de volver a obtener una satisfacción sin resto idéntica a la que se cree haber conocido alguna vez. Es por ello que no hay idealización sin represión.

En cambio, en el campo de la sublimación todo comienza una vez que el sujeto da por perdido lo perdido y avanza en la dirección de su deseo sin otra pretensión que la de continuar deseando. En palabras de Carlos Kuri, los efectos de la sublimación no se verifican necesariamente sobre la persona - en términos de alivio, adaptación o "restitución clínica"44 - sino sobre cierto compuesto pulsional.

\section{Del reloj biológico a la anamorfosis del tiempo en la procreación humana}

Las dificultades que encuentre un sujeto para servirse de la sublimación no dependen, como a veces se cree, de la capacidad de crear, ni del genio que lo acompañe. Siguiendo a Copjec, el obstáculo fundamental que encuentra el sujeto para servirse de la sublimación como destino es la dificultad para dejar atrás aquella pérdida que lo constituye como deseante. Por consiguiente, en tanto permanezca fijado a la condición de goce prescripta por el ldeal en la búsqueda de una supuesta completud perdida, será la repetición de sus fracasos para hallar un objeto capaz de restituirla lo que consuma su empuje pulsional.

En palabras de Copjec:

La fijación [...] en el objeto perdido hace que [el sujeto] sea relativamente indiferente a todos los otros objeto disponibles. Permanece adherido a un ideal que jamás 
${ }^{45}$ COPJEC, 2006, p. 77.
${ }^{46}$ LACAN, 1997, p. 138. Es preciso subrayar que para Lacan el acto de elevar un objeto consiste en suspender su fin de uso, recortarlo de cualquier utilidad que se le haya supuesto, subvirtiendo así su posición en el mercado de los bienes.

${ }^{47}$ Es lo que Copjec explica como la bipartición del objeto que sirve a la satisfacción pulsional, no por alguna característica en particular - aunque hay objetos más idóneos que otros - , sino simplemente porque la pulsión lo ha escogido (Cf. COPJEC, 2006).

${ }^{48}$ Cf. RECALCATI, 2006. alcanzará, puesto que deriva de la nostalgia de algo que jamás poseyó. [...] Las leyes e ideales de la cultura se fabrican pura y exclusivamente sobre la base de la idealización de la insatisfacción. ${ }^{45}$

Para esta autora, la exigencia de trabajo del Superyó se sostiene del ideal que éste pone frente al sujeto, ideal que se mantiene en alto por una pérdida que el sujeto es incapaz de dejar atrás, puesto que de la posibilidad de colmarla depende la ilusión de una satisfacción absoluta. En esta dirección, lo que se busca es el cortocircuito de la pulsión con el objeto que prometa una satisfacción inmediata.

Lo que caracteriza a la sublimación, en cambio, no es la obstinación por el encuentro - o reencuentro del objeto perdido-, sino la sorpresa del hallazgo - de satisfacción en el acto de elevar un objeto ordinario a la "dignidad de la Cosa". ${ }^{46}$ Una vez abandonada toda esperanza de reencuentro con el objeto perdido, se abre para el sujeto la posibilidad del imprevisto.

El hallazgo de objeto, en el caso de la sublimación, no depende de la coincidencia entre cualquier supuesta idoneidad de un objeto para servir a los fines de una satisfacción pulsional sin represión. Por el contrario, es debido a que no se pretende ya alcanzar una satisfacción absoluta - sin resto - que los objetos ordinarios se vuelven pasibles de cierto brillo agalmático. ${ }^{47}$

La sublimación, como destino pulsional, pone en juego cierta temporalidad, no en razón del tiempo cronológico que le demande este proceso a un sujeto en particular, sino en cuanto que no hay sublimación sin recorrido. Nos referimos aquí al trayecto que realiza la pulsión en torno a un vacío y de vuelta hacia el sujeto, trayecto que no carece de obstáculos y vicisitudes ya que el recorrido de la pulsión se dibuja en el límite entre lo simbólico -significantes que organizan el vacío - y el goce - que es la incandescencia eventualmente mortal de ese vacío.

Para Massimo Recalcati, ${ }^{48}$ la sublimación es afín al trabajo de duelo en lo que respecta al uso del tiempo. En ambos casos, se necesita tiempo para efectuar el trabajo simbólico que exige la circunscripción de lo Real. Se trata de una temporalidad que hace posible la transformación de la pulsión.

El tiempo que requiere dicho trayecto sublimatorio no es un tiempo lineal, sino más bien lo que llamaremos un tiempo de escritura. Es preciso pensar en una temporalidad diferente para la sublimación - respecto de los otros destinos de pulsión - ya que en ella no se trata de rememorar una satisfacción perdida, y por ende de una búsqueda de satisfacción directa de ese anhelo.

784 Estudos Feministas, Florianópolis, 21(3): 773-791, setembro-dezembro/2013 
${ }^{49} \mathrm{Cf}$. Claude RABANT, 2009.

${ }^{50}$ LACAN, 1997, p. 383.

\footnotetext{
${ }^{51}$ Con este término - no relación sexual - se hace referencia, en la enseñanza lacaniana, a la disyunción o la no correspondencia unívoca entre significante $y$ significado primero, y más tarde entre el hombre y la mujer, en tanto que seres hablantes y sexuados. Considerando que la sexualidad humana está afectada desde el inicio de la vida por el significante, entre el hombre y la mujer se levanta el muro del lenguaje, que abre el juego de los desencuentros y el malentendido. Allí donde e instinto no deja lugar a dudas para el animal salvaje, el lenguaje introduce todo lo que es del orden del gusto, la atracción, la afinidad, etc., para hombres y mujeres.
}

Si, como lo explica Claude Rabant, ${ }^{49}$ la satisfacción pulsional equivale a la historia de una pasión que puede llevar al sujeto a la muerte, la sublimación es la operación que consigue hacer sobrevivir al sujeto, a cambio de éste renuncie a vivir esa pasión y la relate, la escriba. En palabras de Lacan, "sublimen todo lo que quieran, hay que pagarlo con algo, el goce". ${ }^{50}$

\section{La maternidad como organización de un vacío}

Para el caso de la procreación, tenemos, por un lado, el tratamiento religioso de aquello que definimos como incompresible: que un ser nazca de otro. La religión evita ese agujero y satura de sentido la operación mediante la cual dos seres dan vida a otro. Sacraliza la vida y la eleva a Bien supremo. La ciencia, por otro lado, hace de aquello que resiste cualquier explicación un ámbito más de su saber, soldando el sin-sentido con toda suerte de explicaciones biológicas. Reducir la procreación humana al encuentro aséptico de dos gametos es un claro ejemplo. Desde que se hizo posible separar el encuentro sexual de la procreación, toda una serie de signos parecen funcionar como datos que confirman los presupuestos científicos tendientes a transformar la evidencia científica en la única explicación acerca del desencuentro entre los sexos y sus consecuencias.

En cambio, la procreación como efecto azaroso, inesperado e impensable de un acto de creación da lugar a un proceso de organización que alude a la articulación significante y que no busca llenar el vacío central en el que se produce el nuevo ser, sino que por el contrario, hace de ese vacío el eje en torno del cual giran desde la distribución de las funciones paterna y materna hasta la inscripción del hijo en la cultura.

Sin embargo, la Ciencia facilita hoy una vía inédita en la historia de reproducción humana hasta hace un par de décadas. Se trata de la posibilidad de acceder al hijo sin pasar por el deseo del Otro, del otro sexo, del hombre, de la (no)relación sexual. ${ }^{51}$ La oferta médica tienta en tanto se sostiene de la ilusión de evitar el desencuentro, eludir lo imposible y arribar sin mayores sobresaltos al destino idealizado: un hijo concebido al margen de las diferencias $y$, esto es fundamental, sin demoras.

Las técnicas de Procreación Médicamente Asistida (PMA) han conseguido reducir al macho a su mínima expresión, un gameto, prescindiendo así de su palabra, más no de su deseo - puesto que éste ha de animar a cada donante de semen, incluso cuando ese deseo sea anónimo. 
Intervención médica mediante, se hace posible evadir el desencuentro estructural entre los sexos que la norelación sexual evidencia más acá del ejercicio de la genitalidad, en lo que hace al cruce de deseos entre un hombre y una mujer y a los efectos fecundantes que allí se pueden producir. En el laboratorio, en cambio, en medio del silencio aséptico de las máquinas, no hay desencuentro: los gametos tienen todas las posibilidades de ser encontrados, conjugados, por la mano del biólogo.

Pero sabemos, además, que la medicina procreativa es una medicina de hombres. Es una respuesta instantánea que se orienta desde una lógica fálica para obturar el problema de la falta. Mientras que la feminidad, por el contrario, es una respuesta al vacío, entendido aquí como la ausencia en el Otro de un significante que diga qué es una mujer.

La maternidad puede ser una forma de inscribirse en el Otro bajo un significante que localice a esa mujer, en este caso como Madre. Pero la operación por la cual se accede al hijo es radicalmente diferente en ambos casos. Como respuesta a la falta - en la dirección del goce fálico - un hijo es algo que se tiene, y que podrá luego ocupar el lugar de un sustituto del objeto perdido. En ese caso, el hijo se demanda desde la privación de aquello que se supone debería tenerse para ser.

Como modo de organización del vacío, la maternidad es un lugar posible para la mujer como notoda, es una versión de la feminidad donde el hijo no viene a colmar la falta, sino que viene a responder al deseo que se realiza gracias a la existencia de un vacío. En otras palabras, la búsqueda de un hijo puede representar para una mujer tanto un medio para llenar aquel vacío insondable, como un efecto de creación justamente a

${ }^{52}$ Cf. Silvia Elena TENDLARZ, 2005 propósito del mismo. ${ }^{52}$

El aplazamiento indefinido de la maternidad puede funcionar a los fines de convertir al niño imposible, como producto imprevisto del encuentro con un hombre, en el niño prohibido, completando así el circuito sublimatorio que Freud describe para el hombre. El hijo no se tiene porque no está permitido acceder a él, en tanto representaría un obstáculo a la carrera profesional, o porque no se ha encontrado la pareja adecuada, etc. Se trata aquí de encontrar goce en posponer aquello a lo que tampoco se puede renunciar, puesto que implicaría desobedecer los ideales de la cultura.

En cambio, la procreación en su vertiente de acto es una forma de hacer con el vacío, donde la satisfacción se obtiene no de llenar u obturar dicho vacío, sino de contornearlo y en el recorrido dar a luz una nueva creatura. Es el cruce de 
${ }^{53}$ Cf. LACAN, 1991

${ }^{54}$ Cf. Patricia ALKOLOMBRE, 2008.

${ }^{55}$ CHATEL, 1996, p. 27. deseos con un hombre que la procreación acontece como acto de creación, allí donde una mujer acusa en su vientre ${ }^{53}$ la producción de un sentido nuevo. Lo imposible, aquí, es otro nombre para el vacío a contornear, y no ya una coartada neurótica. A su vez, la producción de un sentido nuevo es efecto de un encuentro imprevisto, un hallazgo inesperado e incalculable, que excede cualquier programación.

En lo que respecta a la denominada maternidad tardía, todo pareciera indicar que allí se trata de un problema de tiempo. La medicina propone una forma de medición, el llamado reloj biológico, que parte del dato fisiológico para localizar un tiempo ideal para la procreación femenina. Dada la medida, los embarazos que se produzcan antes serán considerados precoces, y los que se produzcan después, tardíos.

Para el psicoanálisis, en cambio, todo lo que hace a la creación requiere de tiempo no medible cronológicamente. El tiempo de la procreación es un tiempo lógico. En otras palabras, el instante fecundo para una mujer es aquel en el cual el vacío central que la constituye pierde su incandescencia, su lleno de goce y se abre así la vía de la creación. Ella accede así a otro goce, que no culmina en la obtención de tal o cual objeto, sino que inaugura su particular modalidad de sublimación.

Pero el tratamiento científico de la demanda de hijo en aquellas mujeres que deciden transformarse en madres después de los 35 años desconoce los ritmos de la pulsión, puesto que es incapaz de identificar su pulso. Apura entonces el inicio del tratamiento médico, porque el reloj corre.

En otras palabras, allí donde la medicina identifica como obstáculo o dificultad la edad de la paciente, y orienta sus esfuerzos a producir el hijo a contrarreloj, se produce simultáneamente una interrupción del ritmo subjetivo que caracteriza a la procreación como efecto sublimatorio. Y esto es así siempre que se reduzca la procreación humana a la reproducción de la especie.

Lo que Patricia Alkolombre denomina "pasión de hijo" 54 es el efecto que desencadena la voluntad de acelerar el tiempo de bordear el vacío, tras la promesa de poder dar con un objeto - en este caso el hijo - que colme la falta. Se trata del infierno de la espera, puesto que la promesa de una satisfacción sin resto tienta tanto como horroriza.

Nos referimos aquí a lo que Chatel Ilama "hijos hechos a golpes de voluntad", 55 como resultado de la domesticación del otro goce femenino bajo el reinado del goce fálico de la ciencia de la reproducción.

Sin embargo, el tratamiento médico de la infertilidad como efecto del aplazamiento de la maternidad tiene como resultado, muchas veces, la paradójica situación de que 
${ }^{56}$ Cf. LACAN, 1997.

${ }^{57}$ Cf. Slavoj •|•EK, 2003.

${ }^{58}$ ASSOUN, 1994, p. 218

${ }^{59} \mathrm{Cf}$. CHATEL, 1996 mientras más se aceleran los intentos por producir un hijo, se multiplican los fracasos para conseguirlo.

El correlato subjetivo del apremio médico suele ser la vivencia de que la posibilidad del hijo anhelado es cada vez más remota, a pesar de los esfuerzos que se realizan para alcanzarlo. El hijo imposible es, de esta forma, elevado al lugar de la Cosa y en adelante el tiempo se detiene, se congela. Puesto que allí ya no se trata de alcanzarlo sino, como explica Lacan para el amor cortés, ${ }^{56}$ de postergar siempre un poco más el momento del encuentro. La procreación, que es del orden de lo imposible, es transfigurada aquí en algo del orden de lo prohibido. ${ }^{57}$

Por su parte, la histérica se vale de la ciencia para denunciar justamente la omnipotencia científica. Ella ofrece su cuerpo, se deja hacer, y pone a prueba la impotencia médica para hacerle un hijo. Se trata aquí del reverso del saber-hacer con el vacío - que es como hemos descripto el trabajo sublimatorio -, que consiste en gozar del vacío, es decir, en hacer de aquel una causa de sufrimiento.

\section{Conclusión}

La escucha atenta de mujeres que acuden con su demanda de hijo a un centro médico de tratamiento de la infertilidad nos ha enseñado que en lo que hace a la maternidad, nada puede ser aprehendido de forma directa. Es preciso, por el contrario, seguir la pista de los rodeos que muchas veces las mujeres se imponen para convertirse en madres, a fin de no reducir a lo Real del organismo reproductor femenino esa "especie de sufrimiento creativo que es el síntoma histérico". ${ }^{58}$

Nos referimos concretamente a los avatares que particularizan la búsqueda de embarazo en aquellas mujeres que, habiendo superado la edad ideal para la concepción, apuestan con su cuerpo - y casi sin palabras - en la lotería de la Ciencia, que no puede prometer más que tomar la demanda de hijo al pie de la letra, ${ }^{59}$ fijando en esta operación el pedido multívoco de hijo en una sola dirección.

La fijación de sentido que opera la medicina científica sobre la demanda de hijo reduce a una curva estadística los infinitos volúmenes de la escarpada biología femenina. La compleja cartografía que escribe cada mujer en su trayecto hacia la maternidad se vuelve ilegible para el médico preocupado de contar óvulos, medir hormonas en sangre y transferir a tiempo los embriones fabricados in vitro.

Se hace necesario entonces revertir la progresiva desertificación de la experiencia del cuerpo y del sexo en la procreación y la maternidad, efecto de la Ciencia en el entre-cuerpos que daba origen a un nuevo ser, para localizar 
${ }^{60}$ Cf. Alain BADIOU, 2004.

61 TENDLARZ, 1998, p. 25. Silvia Tendlarz da cuenta en su texto de la segregación y el prejuicio del que suelen ser objeto aquellas mujeres que recurren a la ciencia para acceder a la maternidad fuera de los márgenes considerados socialmente adecuados o deseables. a un sujeto allí donde la mirada del espectador que juzga ${ }^{60}$ - sin más información que la que le ofrecen los medios masivos de comunicación - sólo ve a otra "bruja contemporánea"61 dispuesta a todo para tener un hijo.

En esta investigación nos propusimos abandonar los presupuestos que identifican la maternidad con el destino universal de lo femenino. A partir de allí es posible describir las coordenadas del acceso a la maternidad por otras vías que las de los ideales de la Cultura. Nos referimos específicamente a la maternidad como una modalidad de creación, entre otras formas posibles de bordear el vacío de significación que caracteriza la posición sexuada de una mujer.

La novedad que aporta la perspectiva psicoanalítica al estudio de las nuevas formas de acceso a la maternidad - mediadas por el auxilio médico-científico - consiste justamente en que, para el psicoanálisis, la Madre no recubre necesariamente lo femenino. Por el contrario, la feminidad será para cada mujer un ejercicio de invención cuyo producto es siempre singular.

Será preciso abordar en futuras investigaciones lo que aquí no hemos más que insinuado, esto es, si es posible plantear una modalidad específicamente femenina de creación. Así también se hace indispensable profundizar el diálogo con otras disciplinas para abordar el tema de la maternidad tardía en lo que tiene de complejo y a la vez de novedoso.

\section{Referencias}

AlKolombre, Patricia. Deseo de hijo. Pasión de hijo: Esterilidad y Técnicas

Reproductivas a la luz del Psicoanálisis. 1. ed. Buenos Aires: Letra Viva, 2008

ANDRÉ, Serge. ¿Qué quiere una mujer? 1. ed. Ciudad de México: Siglo XXI, 2002.

ASSOUN, Paul-Laurent. Freud y la mujer. Buenos Aires: Nueva Visión, 1994.

BADIOU, Alain. "La ética: ensayo sobre la conciencia del Mal." In: ABRAHÁM, Tomás. Batallas éticas. 1. ed., Buenos Aires: Nueva Visión, 2004. p. 97-158.

CHAMORRO, Jorge. Las mujeres. 1. ed. Buenos Aires: Gramma, 2008.

CHATEL, Marie-Magdeleine. El malestar en la procreación. Buenos Aires: Nueva Visión, 1996.

COPJEC, Joan. Imaginemos que la mujer no existe: Ética y Sublimación. 1. ed. Buenos Aires: Fondo de Cultura Económica, 2006.

DAVEY, Moyra (Ed.). Maternidad y creación: Lecturas escenciales. 1. ed. Barcelona: Alba, 2001. 
FREUD, Sigmund. "La moral sexual 'cultural' y la nerviosidad moderna" (1908). In: _. Obras completas. 2. ed. Buenos Aires: Amorrortu editores, 2004. p. 159-181. v. 9.

FREUD, Sigmund. "Sobre el psicoanálisis" (1913 [1911]). In: FREUD, Sigmund. Obras completas. 2. ed. Buenos aires: Amorrortu editores, 2004. p. 207-216. v. 12.

GOLDENBERG, Mario (Comp.). De astucias y estragos femeninos. 1. ed. Buenos Aires: Gramma, 2008.

KNIBIEHLER, Yvonne. Historia de las madres y de la maternidad en Occidente. Buenos Aires: Nueva Visión, 2001.

KURI, Carlos. Estética de lo pulsional: Lazo y exclusión entre Psicoanálisis y Arte. 1. ed. Rosario: Homo Sapiens, 2007.

LACAN, Jacques. El Seminario. Libro 3: Las psicosis. 1. ed. Buenos Aires: Paidós, 2002.

LACAN, Jacques. El Seminario. Libro 7: La ética del psicoanálisis. 1. ed. Buenos Aires: Paidós, 1997.

LACAN, Jacques. El seminario. Libro 20: Aún. 1. Ed. Buenos Aires: Paidós, 2004

LACAN, Jacques. "Desescolage". El cartel en el Campo freudiano, Cuadernos de psicoanálisis, Eolia, Buenos Aires, 1991.

LACAN, Jacques. Intervenciones y textos 1. Buenos Aires: Manantial, 2002a.

LAPLANCHE, Jean. La sublimación: Problemáticas III. 1. ed. Buenos Aires: Amorrortu, 2002.

LE POULICHET, Sylvie. El arte de vivir en peligro: Del desamparo a la creación. Buenos Aires: Nueva Visión, 1998.

LOFFREDA, Enrique. Ética y Psicoanálisis: Por el trayecto del deseo. Buenos Aires: Lugar Editorial, 1999.

MILLER, Jacques-Alain. De mujeres y Semblantes. 2. ed. Buenos Aires: Cuadernos del Pasador, 1994.

MILLER, Jacques-Alain. El lenguaje, aparato del goce. 1. ed. Buenos Aires: Colección Diva, 2000.

MILLER, Jacques-Alain. Biología lacaniana y acontecimiento del cuerpo. 1. ed. Buenos Aires: Colección Diva, 2002.

RABANT, Claude. Pasión y Sublimación. 1. ed. Rosario: Homo Sapiens, 2009.

RECALCATI, Massimo. "La sublimación artística y la Cosa". In: RECALCATI, Massimo. Las tres estéticas de Lacan: Arte y Psicoanálisis. 1. ed. Buenos Aires: Del Cifrado, 2006, p. 37-82.

SAMPEDRO, Rosario; GOMEZ, Ma. Victoria; MONTERO, Mercedes. "Maternidad tardía: incidencia, perfiles y discursos". Empiria. Revista de Metodología de Ciencias Sociales, n. 5, p. 11-36, 2002.

SOLER, Colette. Lo que Lacan dijo de las mujeres: estudios de Psicoanálisis. 1. ed. Buenos Aires: Paidós, 2008.

TENDLARZ, Silvia Elena. El psicoanálisis frente a la reproducción asistida. Buenos Aires: Editores Contemporáneos, 1998. 
TENDLARZ, Silvia Elena. Las mujeres y sus goces. 1. ed. Buenos Aires: Colección Diva, 2005.

TORT, Michel. El deseo frío: procreación artificial y crisis de las referencias simbólicas. Buenos Aires: Nueva Visión, 1994.

WAJCMAN, Gérard. EL objeto del siglo. 1. ed. Buenos Aires: Amorrortu, 2001.

-1•EK, Slavoj. Las metástasis del goce: Seis ensayos sobre la mujer y la causalidad. 1. ed. Buenos Aires: Paidós, 2003.

[Recebido em 26 de setembro de 2011 , reapresentado em 6 de março de 2012 e aceito para publicação em 4 de junho 2012]

\section{Maternity and Sublimation: a Psychoanalytical Lecture on Delayed Maternity}

Abstract: The purpose of this work is to interrogate the phenomenon of delayed maternity from the psychoanalytical perspective. We base our study on two notions: the issue of time, related to the way the feminine body works; and the notion of creation, related to human procreation. Time and creation are two fundamental elements regarding the psychoanalytical concept of sublimation. They both constitute a singular way to approach femininity and particularly maternity as one of its destinies.

Key Words: Delayed maternity; Sublimation; Femininity; Procreation; Psychoanalysis. 